\title{
Origins of Children's Helpless and Mastery Achievement Patterns in the Family
}

\author{
Audrey Hokoda and Frank D. Fincham \\ University of Illinois
}

\begin{abstract}
An exploratory study examined the origins of children's motivational patterns in the family by observing 3rd-grade children (10 helpless and 11 mastery-oriented) and their mothers performing a series of solvable and insolvable problem-solving tasks. Mothers of mastery children appeared to show sensitivity and responsiveness to their children's ability perceptions and requests for help. They also appeared to support mastery behaviors in their children by increasing task-focused teaching behaviors and maintaining high-positive affect during the insolvable puzzles. Furthermore, in the face of failures, they retrained their children's low-ability attributions and performance-goal statements, while promoting mastery or taskfocused behaviors. These findings are consistent with the hypothesis that mothers of mastery children may socialize their children's achievement motivation. However, because of the small sample size and other limitations, the results should be interpreted with caution. Several directions are outlined for future research on the familial origins of helpless and mastery patterns in children.
\end{abstract}

Learned helplessness is an important individual difference that affects children's performance in achievement settings (e.g., Diener \& Dweck, 1978; Dweck \& Reppucci, 1973; Elliot \& Dweck, 1988; Fincham \& Cain, 1986). Despite evidence that parents have a consistent and longterm influence on their children's achievement beliefs and performance level (e.g., Estrada, Arsenio, Hess, \& Holloway, 1987; Hess, Holloway, Dickson, \& Price, 1984; McGillicuddy-DeLisi, 1992; Sigel, 1985), few studies have examined parental behaviors that foster particular motivational patterns. This study therefore explored the origins of children's helpless and mastery patterns by examining mother-child interactions in an achievement setting.

\section{Helpless and Mastery Achievement Motivation Patterns in Children}

Past research has described two motivational patterns that children display in challenging achievement situations (e.g., Diener \& Dweck, 1978). Some children, exhibiting a pattern called learned helplessness, become discouraged in the face of difficult problems. Following failure, their performance deteriorates, they show negative affect, they have low expectations for future success, and they attribute the failure to uncontrollable, invariant causes (e.g., ability). On the other hand, a more adaptive motivational pattern is displayed by mastery-oriented children, who are not easily discouraged by difficult achievement problems. In the face

Audrey Hokoda and Frank D. Fincham, Department of Psychology, University of Illinois at Urbana-Champaign.

Correspondence concerning this article should be addressed to Audrey Hokoda, who is now at Department of Psychology, San Diego State University, San Diego, California 92182. Electronic mail may be sent via Internet to ahokoda@sdsu.edu. of failure, they tend to make self-monitoring statements that focus on mastering the task, to make more positive-affective statements, and to maintain high expectations for future success. Their performance does not deteriorate; they often persist, increase their effort, and use more sophisticated problem-solving strategies.

It is widely believed that ability beliefs are central to the development of achievement motivation patterns (e.g., Covington, 1992; Nicholls, 1979; Weiner, 1985). Specifically, low-ability attributions or the failure to maintain a highability belief is thought to be the main mediator of low expectations for future success, lack of persistent achievement behaviors, and negative affect.

Achievement goals also may determine differences in motivational patterns of beliefs, behaviors, and affect (e.g., Ames \& Archer, 1988; Elliot \& Dweck, 1988; Nicholls, 1983). For example, Elliot and Dweck (1988) proposed that children with helpless motivational styles (referred to in this article as "helpless children") have performance goals or goals concerned with documenting their ability level, as well as low confidence in their abilities. Children with mastery-oriented motivational styles (referred to in this article as "mastery children") were proposed to have learning goals, which may lead them to make more self-monitoring versus attributional statements. Furthermore, Ames and Archer (1988) found that individual differences in students' perceptions of the salience of performance versus mastery (learning) goals in the classroom were related to helpless and mastery patterns of beliefs and affect.

Helpless and mastery motivational patterns may occur independent of intellectual abilities (Licht \& Dweck, 1984), but there is evidence that the relationship between these patterns and children's achievement level increases from third to fifth grade (Fincham, Hokoda, \& Sanders, 1989). In addition, Fincham et al. reported that children's attributions and teacher's report of helpless behaviors were stable over 
the 2-year period, and helpless achievement patterns in third grade predicted fifth grade achievement level.

\section{Origins of Helpless and Mastery Achievement Patterns}

Although there is little research on the origins of helpless and mastery achievement patterns, there is increasing evidence that parents influence their children's achievement motivation and performance level. For example, children's achievement beliefs are predicted more by their parents' than by their teachers' achievement beliefs (Entwisle \& Hayduk, 1981), and they are predicted more by their parents' beliefs than by how well the children are doing in school (Parsons, Adler, \& Kaczala, 1982). In fact, mothers' ratings of their children's cognitive abilities predicted the children's expectations for success 5 years later (Stevenson \& Newman, 1986). In addition, parents who attribute their children's failures to their children's ability tend to have children who display helpless behaviors, as measured by ability attributions for failures, performance deterioration following failures, and teacher report of helplessness in the classroom (Fincham \& Cain, 1986; Hokoda, Sanders, \& Fincham, 1987).

Because there is little data on parental behaviors that are related to children's helpless and mastery motivational patterns, the present study examined behavioral interactions of mothers and children when they were doing achievement tasks together. We predicted that mothers would behave in ways that socialize their children's motivational patterns. The following questions were investigated, and specific hypotheses are offered when they can be justified by prior research and theory.

First, are mothers of mastery children more sensitive to their children's ability beliefs? Andrews (1982) found that mothers of helpless children made more derogatory comments about their children's competence, suggesting they were not sensitive to their children's self-worth or ability beliefs (Covington, 1992). In addition, mothers of helpless children made more statements encouraging their children to quit. Thus, we hypothesized that mothers of mastery children would be more sensitive to their children's ability beliefs and would model mastery behaviors by making more task-oriented teaching statements versus statements suggesting the children quit, by making more monitoring versus attributional statements, and by making more statements reflecting positive versus negative affect. They were also expected to structure the goal of the tasks differently by emphasizing learning and task involvement versus performance evaluation or ego involvement.

Second, are mothers' use of teaching strategies related to their children's motivational patterns? Prior research has shown that parents' teaching styles can foster differences in children's achievement (Hess \& McDevitt, 1984; Sigel, 1985). Specifically, use of "high-level distancing" (Sigel, 1985 ) or "indirect-control" strategies (Hess \& McDevitt, 1984), that is, techniques in which parents use questions and explanations to teach or challenge their children, have been proposed to lead to enhanced cognitive growth in children. In contrast, low-distancing or direct-control strategies may involve commands, which have not been found to enhance cognitive growth.

One explanation for this relationship between parents' teaching strategies and children's performance is that directcontrol tactics may influence the children's self-evaluative or motivational processes, which then affect the children's performance (Hess \& McDevitt, 1984). That is, directcontrol strategies may lead the children to believe that only the adults are capable of solving the problems. Likewise, low-distancing techniques may stifle the children's initiative and send a metacommunication that the adults lack confidence in the children's abilities (Elias, Ubriaco, \& Gray, 1985). Therefore, we predicted that mothers of helpless children would use more direct-control tactics, which would lead to their children having low appraisals of their abilities and greater negative affect, whereas mothers of mastery children would use more indirect-control strategies, which promote self-confidence and direct their children's attention toward mastering the task.

Third, are mothers of mastery children more responsive than mothers of helpless children when their children ask for help? Andrews (1982) found that, compared with mothers of mastery children, mothers of helpless children were more likely to be unresponsive or deny their children help when their children requested assistance. This is consistent with widespread evidence that parental behaviors that are responsive and sensitive lead to positive outcomes in their children (for reviews, see Dix, 1992; Maccoby \& Martin, 1983). For example, mothers who respond to their children's questions have children who show more persistent and exploratory behaviors (Skinner, 1986) and who have higher intellectual abilities (Clarke-Stewart, 1977). Related to the concept of responsiveness is the affective tone of mother-child interactions (see Maccoby \& Martin, 1983). In fact, many studies have operationalized parental responsiveness as warmth or positive affect (e.g., Radin, 1971). Parental behaviors that reflect warmth or positive affect have been linked to children's high perceived-academic competence (Wagner \& Phillips, 1992), persistent and exploratory achievement behaviors (Estrada et al., 1987), high-achievement motivation as rated by teachers (Radin, 1971), and high future achievement (Estrada et al., 1987; Hess et al., 1984). To examine whether mothers differ in response to their children's requests for help, we used lag sequential analyses (Bakeman, 1978; Sackett, 1979) to analyze mother-child interactions. We predicted that mothers of helpless children would be less responsive and that mothers of mastery children would show more positive affect in their interactions with their children. It was also predicted that mothers of helpless children might respond in ways that communicated their agreement with their children's low-ability attributions, performance goals, and negative affect.

Last, what maternal behaviors directly precede children's displays of helpless behaviors? Mothers may be more likely 
to make performance-goal and child-low-ability statements, suggest quitting, and show negative affect before their children display helpless beliefs, behaviors, and affect.

\section{Method}

\section{Participants}

Approximately $90 \%$ of the third grade of an elementary school in a small community in the midwestern United States were recruited for this study. On the basis of their responses to two measures of helplessness, 21 children ( 10 helpless and 11 mastery) and their mothers were selected for intensive study. The helpless group comprised 5 boys and 5 girls, with a mean age of 8 years and 6 months. The mastery group had 6 boys and 5 girls, with a mean age of 8 years and 3 months. The groups did not differ in thirdgrade report card evaluations, which was a composite score of their teacher's ratings on various math and reading skills (helpless, $M=35.00, S D=7.04$, and mastery, $M=36.00, S D=$ 3.46). All of the children were Caucasian, and there were no group differences in mothers' and fathers' educational levels. In both groups, about half of the mothers had a high school degree, and the other half had attended college; the majority of fathers had some college education.

\section{Selection of Helpless and Mastery Children}

Unlike past research that relied on a single criterion to identify motivational patterns (e.g., attribution style, Diener \& Dweck, 1978, and behavior, Dweck \& Reppucci, 1973), the present study combined both of the criteria previously used to identify motivational pattern groups. Thus, children were divided into helpless and mastery groups on the basis of a median split of their responses to an attributional style measure and their behaviors on an achievement task. Using this procedure, 21 of the initial sample of 113 children were classified as learned helpless $(19 \%)$, and 27 children were classified as mastery-oriented (24\%). From these groups, 10 helpless ( $48 \%$ of the helpless group) and 11 mastery children ( $41 \%$ of the mastery group) and their mothers were randomly selected to participate in this study. The stringent selection criterion used was designed to minimize error in classifying children into mastery and helpless groups.

Children's attributional style. The Intellectual Achievement Responsibility Scale (IAR; Crandall, Katkovsky, \& Crandall, 1965 ) is a 34-item forced-choice questionnaire; a subscale of 10 items has been widely used to identify helpless and masteryoriented children (e.g., Diener \& Dweck, 1978; Fowler \& Peterson, 1981). Each item in this subscale describes an achievement situation in which the child fails followed by two alternative explanations for the event: an external attribution versus an effort attribution. In past research, children scoring below the median on this subscale were categorized as having a helpless learning style and those scoring above the median were classified as masteryoriented.

Behavioral achievement task. The second measure used to select the children was a behavioral task that assessed the effect of failure on children's performance. This task was patterned after those used in prior research to identify helpless and masteryoriented behaviors (e.g., Dweck \& Reppucci, 1973). That is, children's baseline performance on a task was assessed and compared with their performance on the same task following exposure to failure. The task involved a series of 12 mazes administered in the following order: 2 solvable mazes, 8 insolvable mazes, and 2 solvable mazes that were identical to the initial 2 mazes. To take into account initial base levels of responding, we predicted children's time to solution for the last 2 mazes from their time to solution for the first 2 mazes. The difference between predicted and actual performance was then used to determine the helpless and mastery-oriented groups; following the procedures used in prior research (e.g., Dweck \& Reppucci, 1973), children scoring above the median on this difference score were classified as helpless because their actual time was slower than the predicted time, and children scoring below the median were classified as mastery oriented.

\section{Procedure}

The IAR was administered to the children in their classroom during the last semester of their third-grade year. A few weeks following this group session, the children were observed individually on the achievement tasks measuring their responses to failures.

On the basis of their responses to the IAR and behavioral task, the children and their mothers were then invited during the summer break to participate in a research project at the university. On arrival, they were taken to a room that had a round table with two chairs at it, two bookcases, two desks, and two video cameras on the shelves of the bookcases. The experimenters were two female graduate psychology students. One experimenter explained that the purpose of the study was to examine how children and their parents work on problem-solving tasks. The mothers were given brief instructions, in which they were told they would be doing four tasks and that they would have 5 min to complete each task. The mothers were told to feel free to help or instruct their children in any way they felt comfortable but that they should not manipulate the task materials. After these instructions, they were told they would be starting soon and that in the meantime they could play with the Boggle or Etch A Sketch games that were on the table.

The experimenter then returned to the room with instructions for the first task, which was the solvable version of one of the four tasks. Following the task instructions, the experimenter left the room, and a buzzer rang indicating that they could begin the task. After $5 \mathrm{~min}$, the buzzer rang again, and the experimenter returned after $1 \mathrm{~min}$ to give the instructions for the second task, which was insolvable. Following this task, the experimenter returned with the third task, which was also insolvable. The child and mother then completed a series of questions assessing their performance beliefs and affect about the tasks. Following these questions, the final solvable task was given, and the questions were readministered.

Lastly, the children and mothers were told that they had done well on the puzzles overall. They were told that some of the puzzles were beyond the level expected for the children's age, because one of the purposes of the study was to examine how children approach both difficult and easy puzzles. They were then given the opportunity to watch the videotape of themselves succeeding on the last set of puzzles. Viewing themselves on television was exciting to many of the children and seemed to enhance both the saliency of the successful outcomes and their feelings about their overall performance.

\section{Tasks}

The problem-solving tasks were designed to study parents' influences on children's perceived academic competence (Phillips, 
1982). The tasks were constructed to tap both verbal and spatialvisual skills and to have both solvable and insolvable versions.

Block design. One task was adapted from the Wechsler Intelligence Scale for Children-Revised (1974). The children were shown a card with a four- or nine-block design on it and were asked to replicate the pattern with the blocks they were given.

Anagram task. In this task, the children were asked to choose five letters from an 8 in. $\times 11$ in. $(20.32 \mathrm{~cm} \times 27.94 \mathrm{~cm})$ plastic slide envelope containing 25 pockets (five rows of 5 pockets). Identical letters were placed in the 5 pockets composing each row, and the children chose one letter from each row; thus, regardless of which pocket the children chose, the same letters were obtained. After choosing the letters, the children's task was to unscramble the letters to make one five-letter word.

Gridlock. In this game, there were small plastic chips with shapes stamped out, and these were arranged on a grid resembling a waffle iron. The grid consisted of raised shapes that matched the holes on the chips and were arranged in rows of four shapes and columns of seven shapes. The shapes were squares, triangles, red cross signs, and circles; each chip was either a rectangle containing two shapes or an L-shaped piece containing three shapes. At the outset of each trial, 3 or 4 chips, marked with a black dot, were placed on the grid. The children were asked to place the remaining 12 or 13 chips on the grid so that no raised shapes were left uncovered, and all chips were used.

Compound words. The last task required the children to identify compound words from a scrambled set of simple words. Twelve simple words were printed on 3 in. $\times 5$ in. $(7.62 \mathrm{~cm} \times$ $12.70 \mathrm{~cm}$ ) cards and the children's task was to lay out the cards and match pairs of simple words to create 6 compound words.

\section{Observation of Mother-Child Interactions}

Coding. Verbatim transcripts were made of the child-mother interactions from the videotapes. The transcripts were then divided into expressed ideas or "thought units" (Gottman, 1983). The system used to code maternal behaviors consisted of 17 codes that were distributed under eight broader categories: child-ability attributions, task attributions, attributional versus monitoring statements, achievement goals, affect, quitting versus persistence, indirect- or direct-control teaching strategies, and evaluative feedback. In addition, five child behaviors were coded that served as criterion or antecedent codes in the lag sequential analyses. These behaviors were requesting help, expressing negative affect, quitting, verbalizing a performance goal, and verbalizing a lowability attribution.

Reliability. Two coders, a graduate and an undergraduate student in psychology who did not know the group of each participant, independently rated the sessions of six child-mother pairs or $35 \%$ of the transcribed videotapes. Two kinds of reliability statistics were computed for the behavior codes. First, Cronbach's alpha coefficients were computed as suggested by Wiggins (1973, p. 290 ). For the lag sequential analyses, Cronbach's alpha is not an appropriate reliability index because the index must look at each specific unit coded rather than at the summed frequency of codes over an interaction (Johnson \& Bolstad, 1973). Cohen's kappa (Cohen, 1960) was therefore computed because this procedure examines agreement of specific coding units.

A summary of the mother and child codes and their reliability coefficients is presented in Table 1 . Coefficient alpha for the mother codes ranged from .71 to .99 , with a mean of .91 . Cohen's kappas for the mother codes analyzed lag sequentially ranged from .67 to .97 , with a mean of .89 . The five child codes had alpha coefficients ranging from .88 to .98 with a mean of .95 , and Cohen's kappas ranged from .91 to .96 with a mean of .93 .

\section{Results}

\section{Mother Behavior Codes}

To control for variability in the number of behavioral codes displayed by the child-mother pairs, we converted all codes to proportions and then performed arcsine transformations to stabilize the variance (Myers, 1966). Each transformed code was then analyzed in a 2 (group) $\times 2$ (puzzle condition) analysis of variance, with the second variable treated as a repeated measure. Tests of simple effects in a significant interaction were computed using Bonferroni $t$ statistics. Four comparisons were computed to ascertain group and puzzle condition differences, and therefore the significance level for these tests was set at $.013(.05 \div 4)$. Table 2 shows the means and standard deviations for the 17 mother-behavior codes and a summary of the $F$ ratios and significance levels for the analyses of variance. As noted below, the results provide some support for the hypothesis that mothers of helpless and mastery children differed in behaviors that may socialize their children's motivational patterns.

Attributions. Mothers of mastery children tended to make more attributions to their children's high ability than did mothers of helpless children, a finding that marginally supports the hypothesis that mothers of mastery children would be more sensitive to their children's ability beliefs.

Affect. Mothers of helpless and mastery children also differed in affect; follow-up tests revealed that mothers of helpless children were more likely to make fewer positive affect statements during the insolvable puzzle tasks than during the solvable puzzle tasks, $t(9)=4.05, p<.01$, whereas mothers of mastery children did not differ in the number of positive affect statements they made across puzzle conditions.

Overall teaching. Mothers also differed in teaching behaviors; mothers of mastery children were more likely to increase their use of teaching statements when doing insolvable puzzles than when doing solvable puzzles, $t(10)=$ $4.36, p<.01$. They also did more teaching than mothers of helpless children during the insolvable puzzles, $t(19)=$ $3.13, p<.01$.

Indirect- and direct-control teaching strategies. Contrary to predictions, mothers of helpless children did not use more direct-control strategies than mothers of mastery children. Follow-up tests revealed that mothers of mastery children increased direct-control teaching while working on insolvable puzzles, $t(10)=3.63, p<.01$; they also used more direct-control strategies than mothers of helpless children did when working on insolvable puzzles, $t(19)=4.52$, $p<.01$. 
Table 1

Summary of Mother-and Child-Behavior Codes

\begin{tabular}{|c|c|c|c|}
\hline Behavior codes & Examples & Cronbach's $\alpha$ & Cohen's $\kappa$ \\
\hline \multicolumn{4}{|l|}{ Mother } \\
\hline \multicolumn{4}{|l|}{$\begin{array}{l}\text { Mother } \\
\text { Child ability attribution }\end{array}$} \\
\hline 1. Child's high ability & "You're good at these." & .71 & .67 \\
\hline Task attribution & & & \\
\hline $\begin{array}{l}\text { 2. Task ease } \\
\text { 3. Task difficulty }\end{array}$ & $\begin{array}{l}\text { "These are easy." } \\
\text { "These are hard." }\end{array}$ & .90 & \\
\hline $\begin{array}{l}\text { 3. Task difficulty } \\
\text { Attributions/monitoring }\end{array}$ & & .83 & \\
\hline $\begin{array}{l}\text { Attributions/monitoring } \\
\text { 4. Number of attributions }\end{array}$ & \multicolumn{3}{|c|}{ Attributions/monitoring } \\
\hline 5. Child/Self-monitoring & "Think again." and "Slow down." & .96 & .89 \\
\hline Achievement goals & & & .97 \\
\hline 6. Performance goal & "You got 3 out of 5 right." & .96 & \\
\hline 7. Learning goal & "That's OK; you did your best." & .71 & \\
\hline Affect & & & .95 \\
\hline 8. Positive affect & "This is fun." (smiles, laughs) & .99 & \\
\hline 9. Negative affect & "I don't like this." (pouts, gets angry) & .97 & \\
\hline \multicolumn{4}{|l|}{ Quitting/persistence } \\
\hline 10. Quitting & "Let's leave it." and "Want to move on?" & .83 & .89 \\
\hline 11. Total teaching & "Move that letter." and "Where's this go?" & .97 & \\
\hline Indirect/direct teaching & & & .92 \\
\hline 12. Indirect control & "What's a word that starts with $b$ ?" & .77 & \\
\hline 13. Direct control & "Move that piece right here." & .99 & \\
\hline Evaluative feedback & & & .93 \\
\hline 14. Positive feedback & "Good job." and "That's great." & .97 & \\
\hline 15. Negative feedback & "No, that's wrong." & .99 & \\
\hline 16. Lack of feedback & No response after child's question. & .95 & \\
\hline 17. Neutral feedback & "OK." & .94 & \\
\hline \multicolumn{4}{|l|}{ Child } \\
\hline 1. Low-ability attribution & "I can't do this." & .88 & .91 \\
\hline 2. Performance goal & "How much time do I have left?" & .97 & .91 \\
\hline 3. Negative affect & "I don't like this." (frowning) & .98 & .96 \\
\hline 4. Quitting & "Let's quit and do the next one." & .97 & .91 \\
\hline 5. Requests for help & "Mom, what do I do now?" & .94 & .94 \\
\hline
\end{tabular}

\section{Group Differences in Mothers' Responses to Their Children's Helpless Behaviors}

In lag sequential analysis, a specific code is selected as the criterion (e.g., a child's low-ability statement), and conditional probabilities of each target code (e.g., mother's high-ability statement), given the occurrence of the criterion code, are calculated. The sequences are tested for significance by comparing the conditional and unconditional probabilities of each code using a $z$ statistic (Sackett, 1979). The $z$ scores for sequences that exceed 2.0 are considered significant (Sackett, 1979), and when comparing the sequences of helpless and mastery groups, a difference of 2.0 is considered significant (Gottman \& Parkhurst, 1980).

To determine responses to the children's display of helpless behaviors, we selected four child behaviors as criterion codes: low-ability attribution, performance goal, negative affect, and quitting. Table 3 displays the joint frequencies, conditional probabilities, and $z$ scores for the behavior sequences examined as a function of helpless and mastery groups.

Overall, the results provide support for the hypothesis that mothers of helpless and mastery children would differentially respond to their children's display of helpless behaviors. Mothers of mastery children appeared to retrain their children's helpless beliefs. For example, when their children made low-ability statements, they were more likely than mothers of helpless children to reassure their children of their high ability. When their children made a performancegoal statement, they were more likely to respond with a learning goal. In addition, mothers of mastery children appeared to promote mastery or task-focused behaviors in response to their children's helpless behaviors. When mastery children made a low-ability statement or displayed negative affect, their mothers were likely to respond with a teaching strategy. Although mothers of both helpless and mastery children responded to their children's suggestion of quitting with a quitting statement, mothers of mastery children also responded with a monitoring statement.

Mothers of helpless children did not respond to their children's low-ability attributions with a high-ability statement but instead were likely to suggest quitting. When their children made a performance-goal statement, mothers of helpless children were more likely than mothers of mastery children to respond with a performance goal. Furthermore, when their children displayed negative affect, mothers of helpless children were more likely to reciprocate the negative affect.

\section{Group Differences in Mothers' Responses to Their Children's Requests for Help}

It was expected that mothers might differ in response to their children's requests for help in their use of indirect- and 
Table 2

Means and Standard Deviations of Mother-Behavior Codes and the Results of 2 (Group) $\times 2$ (Puzzle Condition) Repeated-Measures Analyses of Variance

\begin{tabular}{|c|c|c|c|c|c|c|c|c|c|c|c|}
\hline \multirow[b]{3}{*}{ Mother codes } & \multicolumn{4}{|c|}{ Group } & \multicolumn{4}{|c|}{ Main effects } & \multirow{2}{*}{\multicolumn{2}{|c|}{$\frac{\text { Interaction }}{\text { Group } \times \text { Puzzle }}$}} & \multirow[b]{3}{*}{ Direction of effects } \\
\hline & \multicolumn{2}{|c|}{ Solvable } & \multicolumn{2}{|c|}{ Insolvable } & \multicolumn{2}{|c|}{ Group } & \multicolumn{2}{|c|}{ Puzzle } & & & \\
\hline & LH & MO & LH & MO & $F$ & $p$ & $F$ & $p$ & $F$ & $p$ & \\
\hline \multicolumn{12}{|l|}{ Child-ability attribution } \\
\hline Child's high ability & & & & & 3.45 & .08 & & & & & $\mathrm{MO}>\mathrm{LH}$ \\
\hline $\begin{array}{l}M \\
S D\end{array}$ & 0.3 & 1.2 & 0.1 & 0.8 & & & & & & & \\
\hline \multicolumn{11}{|l|}{$\begin{array}{l}\text { Task attribution } \\
\text { Task ease }\end{array}$} & \\
\hline \multicolumn{12}{|l|}{ Task ease } \\
\hline$M$ & 0.3 & 0.7 & 0.3 & 0.5 & & & \multirow{5}{*}{7.57} & & & & \\
\hline$S D$ & 0.5 & 0.9 & 0.9 & 0.9 & & & & \multirow{4}{*}{.01} & & & \multirow{4}{*}{ Insol $>$ Sol } \\
\hline Task difficulty & & & & & & & & & & & \\
\hline$M$ & 0.3 & 0.5 & 1.3 & 0.7 & & & & & & & \\
\hline$S D$ & 0.5 & 0.8 & 1.3 & 1.0 & & & & & & & \\
\hline \multicolumn{12}{|l|}{ Attributions/monitoring } \\
\hline $\begin{array}{l}\text { Number of attributions } \\
M\end{array}$ & 2.5 & 3.0 & 4.7 & 4.5 & & & 7.01 & .02 & & & Insol $>$ Sol \\
\hline$S D$ & 1.7 & 2.4 & 3.8 & 4.2 & & & & & & & \\
\hline Child/Self-monitoring & & & & & & & 3.34 & .08 & & & Insol $>$ Sol \\
\hline$M$ & 4.3 & 5.0 & 5.1 & 8.1 & & & & & & & \\
\hline $\begin{array}{l}\quad S D \\
\text { Achievement goals }\end{array}$ & 2.3 & 3.9 & 3.3 & 5.7 & & & & & & & \\
\hline $\begin{array}{l}\text { Achievement goals } \\
\text { Performance goal }\end{array}$ & & & & & & & & & & & \\
\hline$M$ & 4.2 & 4.1 & 5.3 & 3.5 & & & & & & & \\
\hline$S D$ & 4.3 & 3.2 & 5.4 & 2.4 & & & & & & & \\
\hline Learning goal & & & & & & & & & & & \\
\hline$M$ & 0 & 0.4 & 0.6 & 0.6 & & & & & & & \\
\hline$S D$ & & 0.7 & 1.1 & 0.8 & & & & & & & \\
\hline Affect & & & & & & & & & & & \\
\hline Positive affect & & & & & & & 7.69 & .01 & 4.97 & .04 & LH-Insol < LH-Sol \\
\hline$M$ & 0.6 & 0.7 & 1.0 & 1.8 & & & 2.00 & .10 & & & IIIS OT TOI \\
\hline$S D$ & 1.3 & 1.8 & 1.9 & 3.4 & & & & & & & \\
\hline Quitting/persistence & & & & & & & & & & & \\
\hline Quitting & & & & & & & 8.67 & .01 & & & Insol $>$ Sol \\
\hline$M$ & 0.2 & 0.3 & 1.4 & 1.2 & & & & & & & \\
\hline$S D$ & 0.4 & 0.9 & 1.3 & 1.0 & & & & & & & \\
\hline Total teaching & & & & & 6.64 & .02 & 14.30 & .001 & 4.49 & .05 & MO-Insol > MO-Sol \\
\hline $\begin{array}{l}M \\
S D\end{array}$ & 14.3 & 20.4 & 19.4 & $\begin{array}{l}41.4 \\
22.3\end{array}$ & & & & & & & MO-Insol > LH-Insol \\
\hline $\begin{array}{l}S D \\
\text { Indirect/direct teaching }\end{array}$ & 9.5 & 13.6 & 10.8 & 22.3 & & & & & & & \\
\hline $\begin{array}{l}\text { Indirect/direct teaching } \\
\text { Indirect control }\end{array}$ & & & & & & & & & & & \\
\hline$M$ & 2.9 & 2.3 & 1.8 & 7.0 & & & & & & & \\
\hline$S D$ & 3.1 & 4.1 & 2.1 & 8.3 & & & & & & & \\
\hline Direct control & & & & & 10.48 & .01 & 6.80 & .02 & 4.27 & .05 & MO-Insol > MO-Sol \\
\hline$M$ & 5.7 & 9.9 & 6.1 & 18.1 & & & & & & & MO-Insol > LH-Insol \\
\hline$S D$ & 5.2 & 7.2 & 4.2 & 9.1 & & & & & & & \\
\hline Evaluative feedback & & & & & & & & & & & \\
\hline$\underset{M}{\text { Positive feedback }}$ & & & & & & & & & & & \\
\hline $\begin{array}{l}M \\
S D\end{array}$ & $\begin{array}{l}9.3 \\
6.3\end{array}$ & $\begin{array}{l}8.9 \\
9.4\end{array}$ & $\begin{array}{l}8.2 \\
8.5\end{array}$ & $\begin{array}{r}10.3 \\
9.0\end{array}$ & & & & & & & \\
\hline Negative feedback & & & & & & & 7.09 & .02 & & & Insol > Sol \\
\hline$M$ & 6.0 & 6.5 & 7.9 & 10.5 & & & & & & & \\
\hline$S D$ & 4.2 & 6.0 & 4.9 & 5.0 & & & & & & & \\
\hline Lack of feedback & & & & & & & & & & & \\
\hline$M$ & 1.2 & 1.9 & 1.2 & 0.9 & & & & & & & \\
\hline$S D$ & 1.4 & 2.3 & 1.6 & 1.0 & & & & & & & \\
\hline Neutral feedback & & & & & & & & & & & \\
\hline $\begin{array}{l}M \\
S D\end{array}$ & $\begin{array}{r}13.6 \\
5.7\end{array}$ & $\begin{array}{r}11.9 \\
4.9\end{array}$ & $\begin{array}{r}11.9 \\
4.7\end{array}$ & $\begin{array}{r}12.5 \\
8.5\end{array}$ & & & & & & & \\
\hline
\end{tabular}

Note. Only significant main effects and interactions are shown. $\mathrm{LH}=$ learned helpless; $\mathrm{MO}=$ mastery-oriented; Insol $=$ insolvable condition; Sol = solvable condition. 
Table 3

Results of Lag Sequential Analyses Examining Mothers' Responses to Their Children's Helpless Behaviors as a Function of Helpless and Mastery Child-Mother Pairs

\begin{tabular}{|c|c|c|c|c|c|c|}
\hline \multirow[b]{2}{*}{$\begin{array}{c}\text { Consequent ( } \operatorname{Lag} 1) \text { : } \\
\text { Mother behaviors }\end{array}$} & \multicolumn{3}{|c|}{ Helpless group } & \multicolumn{3}{|c|}{ Mastery group } \\
\hline & $\begin{array}{l}\text { Joint } \\
\text { frequency }\end{array}$ & $\begin{array}{l}\text { Conditional } \\
\text { probability }\end{array}$ & $z$ & $\begin{array}{c}\text { Joint } \\
\text { frequency }\end{array}$ & $\begin{array}{l}\text { Conditional } \\
\text { probability }\end{array}$ & $z$ \\
\hline \multicolumn{7}{|c|}{ Antecedent $($ Lag 0 ) = child low-ability behavior } \\
\hline High-ability statement & 0 & .0 & 0.00 & 3 & .07 & $4.87^{*}$ \\
\hline Teaching strategies & 2 & .12 & 0.64 & 6 & .34 & $2.32^{*}$ \\
\hline Monitoring & - & - & - & - & 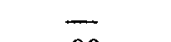 & - \\
\hline Quitting & 2 & .1 & $2.64^{*}$ & 0 & .00 & 0.26 \\
\hline Positive affect & - & $\underline{-}$ & - & - & - & - \\
\hline Negative affect & - & 一 & - & - & - & 一 \\
\hline \multicolumn{7}{|c|}{ Antecedent $(\operatorname{Lag} 0)=$ child performance goal } \\
\hline Performance goal & 4 & .38 & $5.03 *$ & 1 & .03 & 1.07 \\
\hline Learning goal & 0 & .0 & -0.12 & 3 & .06 & $6.14^{*}$ \\
\hline Teaching strategies & - & $\overline{-}$ & - & - & - & - \\
\hline Monitoring & 2 & .20 & $2.72^{*}$ & 5 & .18 & $3.09^{*}$ \\
\hline Positive affect & - & - & - & 一 & 一 & - \\
\hline Negative affect & - & - & 一 & - & - & - \\
\hline \multicolumn{7}{|c|}{ Antecedent $(\operatorname{Lag} 0)=$ child negative affect } \\
\hline High-ability statement & - & - & - & - & - & - \\
\hline Teaching strategies & 6 & .09 & -0.14 & 30 & .29 & $2.31^{*}$ \\
\hline Monitoring & - & 一 & - & - & 一 & 一 \\
\hline Quitting & - & - & - & - & - & 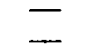 \\
\hline Negative affect & $\overline{6}$ & $\overline{.04}$ & $2 \overline{2.74} *$ & $\overline{2}$ & $\overline{.01}$ & 0.45 \\
\hline \multicolumn{7}{|c|}{ Antecedent $(\operatorname{Lag} 0)=$ child quitting } \\
\hline Quitting & 3 & .10 & $3.68^{*}$ & 2 & .08 & $2.95^{*}$ \\
\hline Teaching strategies & - & - & - & - & - & - \\
\hline Monitoring & 2 & .13 & 1.55 & 6 & .16 & $3.65^{*}$ \\
\hline Positive affect & - & - & $\longrightarrow$ & 一 & 一 & - \\
\hline Negative affect & - & - & - & - & - & - \\
\hline
\end{tabular}

direct-control teaching strategies, evaluative feedback, responsiveness, and affect. These variables were therefore selected as target codes.

The results, displayed in Table 4, provide support for the hypothesis that mothers of helpless children are less responsive to their children. Specifically, they were more likely not to respond or offer help when their children requested it, whereas this sequence was not significant for mastery mother-child pairs.

In addition, mothers of both helpless and mastery children followed up children's help requests with direct-teaching statements. Thus, again, there was no evidence for the hypothesis that mothers' use of direct-control teaching strategies would relate to their children's helplessness patterns.

\section{Mothers' Behaviors That Elicit Their Children's Helpless Behaviors}

To examine mothers' behaviors that directly preceded their children's display of helpless behaviors, we performed a final lag sequential analysis combining the mother-child interactions of both groups. In this analysis, the child criterion behaviors were low-ability attributions, performance goals, negative affect, and quitting, and we compared the conditional probabilities of the target mother codes at lag -1 with their probability of occurring by chance.

Table 5 displays the joint frequencies, conditional probabilities, and $z$ scores for these behavior sequences. The results suggest that mothers' performance-goal statements were likely to elicit both performance-goal statements $(z=$ $2.81)$ and negative affect from their children $(z=2.84)$. In addition, mothers' suggestion of quitting was likely to precede their children's making a quitting statement $(z=$ 10.28).

\section{Discussion}

This exploratory study provides some evidence that the family may be an important influence on the development of children's achievement motivation patterns. Mothers of helpless and mastery children differed in behaviors that may 
Table 4

Lag Sequential Analysis Examining Mothers' Responses to Their Children's Requests for Help as a Function of Helpless and Mastery Child-Mother Pairs

\begin{tabular}{|c|c|c|c|c|c|c|}
\hline \multirow[b]{2}{*}{$\begin{array}{l}\text { Consequent (Lag 1): } \\
\text { Mother behaviors }\end{array}$} & \multicolumn{3}{|c|}{ Helpless group } & \multicolumn{3}{|c|}{ Mastery group } \\
\hline & $\begin{array}{c}\text { Joint } \\
\text { frequency }\end{array}$ & $\begin{array}{l}\text { Conditional } \\
\text { probability }\end{array}$ & $z$ & $\begin{array}{c}\text { Joint } \\
\text { frequency }\end{array}$ & $\begin{array}{l}\text { Conditional } \\
\text { probability }\end{array}$ & $z$ \\
\hline \multicolumn{7}{|l|}{ Teaching strategies } \\
\hline Indirect & - & - & - & - & - & - \\
\hline Direct & 3 & .14 & $3.85^{*}$ & 7 & .13 & $2.11^{*}$ \\
\hline Other & - & - & - & - & - & - \\
\hline \multicolumn{7}{|l|}{ Evaluative feedback } \\
\hline Positive & 一 & - & - & - & - & - \\
\hline Negative & - & - & - & 一 & - & 一 \\
\hline $\begin{array}{l}\text { No response/Lack of } \\
\text { help affect }\end{array}$ & 8 & .08 & $4.34^{*}$ & 0 & .00 & -0.13 \\
\hline Positive & 一 & - & - & 一 & - & - \\
\hline Negative & - & - & - & - & - & - \\
\hline
\end{tabular}

promote differences in their children's achievement orientation (e.g., Covington, 1992; Nicholls, 1983).

Analyses of the frequencies of mothers' behaviors suggest that mothers of mastery children may be more sensitive to their children's ability beliefs or self-worth beliefs (Covington, 1992) because they tended to make more attributions to their children's high ability than did mothers of helpless children. These findings are consistent with the view that children adopt the same attributions their parents make for the children's behaviors (Dix \& Grusec, 1985).

The results also support the hypothesis that mothers of helpless and mastery children would differ in affect and teaching behaviors. In the face of failures, mothers of helpless children showed less positive affect and failed to increase mastery or task-focused teaching statements. This pattern was similar to the increase in negative affect and performance deterioration that helpless children have displayed without their mothers present (Diener \& Dweck, 1978; Dweck \& Reppucci, 1973). In contrast, mothers of mastery children maintained high positive affect and increased task-oriented behaviors during the insolvable puzzles, which is behaviorally similar to the positive affect and persistence demonstrated by mastery children working alone on difficult achievement tasks.

Some evidence was obtained to support the hypothesis that mothers of mastery children would display behaviors that may optimize their children's motivation in that they seemed to diminish their children's ego-involved or helpless behaviors while promoting mastery or task-oriented behaviors (Nicholls, 1983, 1984). For example, following their children's low-ability attributions, mothers of mastery children were likely to respond with a teaching strategy, thereby shifting attention away from ability evaluation and back toward mastering the task. In addition, they seemed to enhance their children's ability or self-worth beliefs (Covington, 1992) by reassuring their children of their high ability in response to their children's low-ability statements. Thus, mothers of mastery children both addressed their children's maladaptive belief by immediately contradicting a low-ability statement, while providing an effective coping response by making a teaching or task-focused statement (Meichenbaum, 1977).

When helpless children made low-ability attributions, their mothers were not likely to respond with a teaching or high-ability statement. Rather, they tended to respond with a suggestion that the children quit or move on to the next puzzle (e.g., child says "I can't come up with anything at all," and mother responds "OK, let's go on to the next one"). There were no group differences in mothers' tendency to quit, and in the insolvable condition quitting might be adaptive, but the timing of this behavior may be important. In response to a child's low-ability statement, suggestions of quitting may communicate an implicit agreement with the child's low-ability statement.

The response of mothers with mastery-oriented children is illustrated in the following interchange.

\author{
Mastery child: I can't do it. \\ Mother: Try, stick with it. Come on. \\ Child: I can't do this one. \\ Mother: Yes, you can. \\ Child: I can't. \\ Mother: Look at this one. \\ This one is solid white.
}

This mother responded initially with a monitoring statement, next a high-child-ability statement, and third a teaching strategy. She seemed to promote mastery behaviors by redirecting the child back to the task, and she also retrained the low-ability attribution. Mothers of helpless children did not invalidate their children's maladaptive ability beliefs or promote mastery responses, but instead implicitly accepted low-ability statements by suggesting 
Table 5

Lag Sequential Analysis Examining Mothers' Behaviors That Elicit Their Children's Helpless Behaviors

\begin{tabular}{|c|c|c|c|c|}
\hline \multirow{2}{*}{$\begin{array}{l}\text { Antecedents }(\mathrm{Lag}-1) \\
\text { Mother behaviors }\end{array}$} & \multicolumn{4}{|c|}{ Lag $0=$ child helpless behaviors } \\
\hline & Low ability & Performance goal & Quit & Negative affect \\
\hline \multicolumn{5}{|l|}{ High-child-ability attribution } \\
\hline Joint frequencies & - & - & - & - \\
\hline Conditional probabilities & - & - & - & - \\
\hline \multirow{2}{*}{\multicolumn{5}{|c|}{ Performance goal }} \\
\hline & & & & \\
\hline Joint frequencies & - & 9.00 & - & 11.00 \\
\hline Conditional probabilities & - & 0.05 & - & 0.03 \\
\hline & - & $2.81^{*}$ & - & $2.84^{*}$ \\
\hline \multicolumn{5}{|l|}{ Learning goal } \\
\hline Joint frequencies & - & - & - & - \\
\hline Conditional probabilities & - & - & - & - \\
\hline \multirow{2}{*}{\multicolumn{5}{|c|}{ Quitting }} \\
\hline & & & & \\
\hline Joint frequencies & - & - & 6.00 & - \\
\hline Conditional probabilities & - & - & 0.16 & - \\
\hline$z$ & - & - & $10.28^{*}$ & - \\
\hline \multicolumn{5}{|l|}{ Teaching strategies } \\
\hline Joint frequencies & - & - & - & - \\
\hline Conditional probabilities & - & - & - & - \\
\hline \multirow{2}{*}{\multicolumn{5}{|c|}{ Monitoring }} \\
\hline & & & & \\
\hline Joint frequencies & - & - & - & - \\
\hline Conditional probabilities & - & - & - & - \\
\hline \multirow{2}{*}{\multicolumn{5}{|c|}{ Positive affect }} \\
\hline & & & & \\
\hline Joint frequencies & - & - & - & - \\
\hline Conditional probabilities & - & - & - & - \\
\hline \multirow{2}{*}{\multicolumn{5}{|c|}{ Negative affect }} \\
\hline & & & & \\
\hline Joint frequencies & - & - & - & - \\
\hline Conditional probabilities & - & - & - & - \\
\hline$z$ & - & - & - & - \\
\hline
\end{tabular}

Note. Data are provided only for $z$ scores that were significant.

${ }^{*} p<.05$.

quitting. Because ability beliefs are central to the development of achievement motivation patterns (e.g., Nicholls, 1979; Weiner, 1985), these behavioral differences in mothers' responses to their children's low-ability statements may be particularly important.

Further evidence that mothers may reinforce their children's motivational patterns is provided by the results on mothers' achievement goals. It had been expected from past research (Ames \& Archer, 1987; Elliot \& Dweck, 1988) that mothers of helpless children would be more likely to create an environment emphasizing performance goals, which would then promote patterns of helplessness. Surprisingly, mothers of helpless and mastery children did not differ in how often they made statements reflecting performance and learning goals. However, the lag sequential analyses indicated that the timing and context of mothers' goal statements may be important. Following children's performance-goal statements, mothers of helpless children were more likely to validate the goal and respond with a performance goal, whereas mothers of mastery children were more likely to respond with a learning goal. Thus, mothers of mastery children appeared to socialize their children's goal by deemphasizing performance evaluation (e.g., Ames \& Archer, 1987; Elliot \& Dweck, 1988), whereas mothers of helpless children did not invalidate the performance concern.

Mothers of mastery children engaged in other instructional behaviors that may decrease their children's helpless or ego-involved behaviors and promote mastery or taskoriented behaviors (Nicholls, 1983, 1984). They were more likely to ignore their children's negative affect and to respond with a teaching strategy, which again, seemed to redirect the children toward mastering the task. Mothers of helpless children were likely to reciprocate their children's negative affect, which validated their children's feelings and modeled a more helpless response to the insolvable puzzles. In addition, mothers of helpless and mastery children differed in response to their children's quitting. Although mothers of both groups were likely to respond with a quitting statement, mothers of mastery children were also likely to respond with a monitoring statement, again promoting a mastery behavior.

The results also support the hypothesis that mothers of helpless children may be less responsive to their children. 
First, mothers of helpless children did not adapt their teaching behaviors as a function of the solvability of the tasks, whereas mothers of mastery children increased their teaching during the insolvable puzzles. Second, the lag sequential analyses revealed that mothers of helpless children were more likely to give no feedback when their children asked for help. Thus, mothers of helpless children appeared to be modeling helpless behaviors by becoming passive and unproductive during the achievement tasks. The results are consistent with research demonstrating the importance of responsive parenting to children's development (Dix, 1992; Skinner, 1986).

Although causal statements cannot be made about the relationship between mothers' and their children's behaviors (Bell, 1968), mothers' lack of responsiveness may promote a cycle of helplessness in that the children continue to be exposed to noncontingent feedback (Seligman, 1975). That is, a lack of responsiveness could maintain children's helplessness in that they are subjected to an uncontrollable situation in which, despite active attempts to elicit help, no help is available.

A final goal of this study was to identify maternal behaviors that directly precede helpless and mastery children's display of helpless behavior. As predicted, mothers' suggestions of quitting elicited quitting by their children. In addition, mothers' performance-goal statements led to their children making performance-goal and negative affective statements. These findings support the hypothesis that mothers can influence their children's display of helpless behaviors by the way they structure task goals (Ames \& Archer, 1987). Moreover, they provide further evidence that goals are important in determining achievement motivation in children (Elliot \& Dweck, 1988; Nicholls, 1983, 1984).

In summary, this study provides evidence that children's achievement motivation patterns may originate in the family. The results, however, should be considered preliminary and interpreted with caution. First, the results need to be replicated before they can be interpreted with confidence. Second, the small sample size did not allow the study of gender differences, an important omission in view of evidence of gender differences in children's achievement beliefs and affect (Eccles, 1983), mothers' achievement beliefs about their children (daughter vs. son; Martin \& Johnson, 1992), and mothers' achievement behaviors with their children (daughter vs. son; Hess \& McDevitt, 1984).

Third, the behavioral coding system devised for this study warrants further investigation. Specifically, the motherchild interactions should be examined to determine whether these behavioral patterns derived from the coding system are stable over time and ecologically valid across other achievement situations (e.g., when mothers are helping their children with schoolwork at home).

Fourth, because the data are correlational, it cannot be determined whether differences in the mothers' behaviors caused their children's achievement orientation. Past experiences with their helpless or mastery children may have led the mothers to behave differently. Furthermore, confounding variables may account for the group differences in mothers' behaviors.
In view of these limitations, the main contribution of this study is that it points to the importance of studying behavioral interactions in the family as an area of future research in the development of children's achievement motivation patterns. The results suggest that the method used to study family influences on children's achievement motivation should use a dyadic bidirectional approach to studying parent-child interactions (Sigel \& Parke, 1987) and data analytic procedures that include lag sequential analyses (Bakeman, 1978; Sackett, 1979) because these methods showed that mothers differed in behavioral responses to their children's helpless behaviors and that mothers' performance-goal statements may elicit helpless behaviors by their children.

\section{References}

Ames, C., \& Archer, J. (1987). Mothers' beliefs about the role of ability and effort in school learning. Journal of Educational Psychology, 79, 409-414.

Ames, C., \& Archer, J. (1988). Achievement goals in the classroom: Student learning strategies and motivation processes. Journal of Educational Psychology, 80, 260-267.

Andrews, D. E. (1982). Origins of helpless and mastery orientations towards achievement situations among children: Differences in the behavioral profiles of mothers of helpless versus mothers of mastery children. Unpublished doctoral dissertation, State University of New York at Stony Brook.

Bakeman, R. (1978). Untangling streams of behavior: Sequential analyses of observational data. In G. P. Sackett (Ed.), Observing behavior: Vol. 2. Data collection and analysis methods (pp. 63-78). Baltimore: University Park Press.

Bell, R. Q. (1968). A reinterpretation of the direction of effects in studies of socialization. Psychological Review, 75, 81-95.

Clarke-Stewart, K. A. (1977). A review of research and some propositions for policy: Child care in the family. New York: Academic Press.

Cohen, J. A. (1960). A coefficient of agreement for nominal scales. Educational and Psychological Measurement, 20, 37-46.

Covington, M. V. (1992). Making the grade. Cambridge, England: Cambridge University Press.

Crandall, V. C., Katkovsky, W., \& Crandall, V. J. (1965). Children's belief in their own control of reinforcements in intellectual academic achievement situations. Child Development, 36, 91-109.

Diener, C. I., \& Dweck, C. S. (1978). An analysis of learned helplessness: Continuous changes in performance, strategy, and achievement cognitions following failure. Journal of Personality and Social Psychology, 36, 451-462.

Dix, T. (1992). Parenting on behalf of the child: Empathic goals. In I. E. Sigel, A. V. McGillicuddy-DeLisi, \& J. J. Goodnow (Eds.), Parental belief systems (2nd ed., pp. 319-346). Hillsdale, NJ: Erlbaum.

Dix, T. H., \& Grusec, J. E. (1985). Parent attribution processes in the socialization of children. In I. Sigel (Ed.), Parental belief systems: Their psychological consequences for children (pp. 201-233). Hillsdale, NJ: Erlbaum.

Dweck, C. S., \& Reppucci, N. D. (1973). Learned helplessness and reinforcement responsibility in children. Journal of Personality and Social Psychology, 25, 109-116.

Eccles, J. (1983). Expectancies, values, and academic behaviors. In J. T. Spence (Ed.), Achievement and achievement motives: 
Psychological and sociological approaches (pp. 75-146). San Francisco: Freeman.

Elias, M. J., Ubriaco, M., \& Gray, J. (1985). A cognitivebehavioral analysis of parental facilitation of children's socialcognitive problem solving. Journal of Applied Developmental Psychology, 6, 57-72.

Elliot, E. S., \& Dweck, C. S. (1988). Goals: An approach to motivation and achievement. Journal of Personality and Social Psychology, 54, 5-12.

Entwisle, D. R., \& Hayduk, L. A. (1981). Academic expectations and the school attainment of young children. Sociology of Education, 54, 34-50.

Estrada, P., Arsenio, W. F., Hess, R. D., Holloway, S. D. (1987). Affective quality of the mother-child relationship: Longitudinal consequences for children's school-relevant cognitive functioning. Developmental Psychology, 23, 210-215.

Fincham, F. D., \& Cain, K. M. (1986). Learned helplessness in humans: A developmental analysis. Developmental Review, 6, 301-333.

Fincham, F. D., Hokoda, A., \& Sanders, R. Jr. (1989). Learned helplessness, test anxiety, and academic achievement: A longitudinal analysis. Child Development, 60, 138-145.

Fowler, J. W., \& Peterson, P. L. (1981). Increasing reading persistence and altering attributional style of learned helpless children. Journal of Educational Psychology, 73, 251-260.

Gottman, J. M. (1983). How children become friends. Monographs of the Society for Research in Child Development, 48(3, Serial No. 201).

Gottman, J. M., \& Parkhurst, J. T. (1980). A developmental theory of friendship and acquaintanceship processes. In W. A. Collins (Ed.), Minnesota symposia on child psychology (Vol. 13). Hillsdale, NJ: Erlbaum.

Hess, R. D., Holloway, S. D., Dickson, W. P., \& Price, G. G. (1984). Maternal variables as predictors of children's school readiness and later achievement in vocabulary and mathematics in sixth grade. Child Development, 55, 1902-1912.

Hess, R. D., \& McDevitt, T. M. (1984). Some cognitive consequences of maternal intervention techniques: A longitudinal study. Child Development, 55, 2017-2030.

Hokoda, A. J., Sanders, R., Jr., \& Fincham, F. D. (1987, April). Comparing mothers' achievement-related beliefs to their child's achievement patterns in academic settings. Paper presented at the Midwestern Psychological Association, Chicago.

Johnson, S. M., \& Bolstad, O. D. (1973). Methodological issues in naturalistic observation: Some problems and solutions for field research. In L. A. Hamerlynck, L. C. Handy, \& E. J. Mash (Eds.), Behavior change: Methodology, concepts and practice (pp. 7-67). Champaign, IL: Research Press.

Licht, B. G., \& Dweck, C. S. (1984). Determinants of academic achievement: The interaction of children's achievement orientations with skill area. Developmental Psychology, 20, 628-636.

Maccoby, E. E., \& Martin, J. A. (1983). Socialization in the context of the family: Parent-child interaction. In P. H. Mussen (Series Ed.) \& E. M. Hetherington (Vol. Ed.), Handbook of child psychology: Vol. 4. Socialization, personality, and social development (4th ed., pp. 1-101). New York: Wiley.

Martin, C. A., \& Johnson, J. E. (1992). Children's self-perceptions and mothers' beliefs about development and competencies. In I. E. Sigel, A. V. McGillicuddy-DeLisi, \& J. J. Goodnow (Eds.),
Parental belief systems (2nd ed., pp. 95-114). Hillsdale, NJ: Erlbaum.

McGillicuddy-DeLisi, A. V. (1992). Parents' beliefs and children's personal-social development. In I. E. Sigel, A. V. McGillicuddy-DeLisi, \& J. J. Goodnow (Eds.), Parental belief systems (2nd ed., pp. 115-142). Hillsdale, NJ: Erlbaum.

Meichenbaum, D. H. (1977). Cognitive behavior modification. New York: Plenum.

Myers, J. L. (1966). Fundamentals of experimental design. Boston: Allyn and Bacon.

Nicholls, J. G. (1979). Quality and equality in intellectual development: The role of motivation in education. American Psychologist, 34, 1071-1084.

Nicholls, J. G. (1983). Conceptions of ability and achievement motivation: A theory and its implications for education. In S. G. Paris, G. M. Olson, \& H. W. Stevenson (Eds.), Learning and motivation in the classroom (pp. 211-237). Hillsdale, NJ: Erlbaum.

Nicholls, J. G. (1984). Conceptions of ability and achievement motivation. In R. E. Ames \& C. Ames (Eds.), Research on motivation in education (pp. 39-73). New York: Academic Press.

Parsons, J. E., Adler, T. F., \& Kaczala, C. M. (1982). Socialization of achievement attitudes and beliefs: Parental influences. Child Development, 53, 310-321.

Phillips, D. (1982). Parent-child perceived competence task battery. Unpublished manuscript, University of Illinois.

Radin, N. (1971). Maternal warmth, achievement motivation and cognitive functioning in lower-class preschool children. Child Development, 42, 1560-1565.

Sackett, G. P. (1979). The lag sequential analysis of contingency and cyclicity in behavioral interaction research. In J. D. Osofsky (Ed.), Handbook of infant development (pp. 623-649). New York: Wiley.

Seligman, M. E. P. (1975). Helplessness. San Francisco: Freeman. Sigel, I. E. (1985). Parental belief systems: The psychological consequences for children. Hillsdale, NJ: Erlbaum.

Sigel, I. E., \& Parke, R. D. (1987). Structural analysis of parentchild research models. Journal of Applied Developmental Psychology, 8, 123-137.

Skinner, E. A. (1986). The origins of young children's perceived control: Mother contingent and sensitive behavior. International Journal of Behavioral Development, 9, 359-382.

Stevenson, H. W., \& Newman, R. S. (1986). Long-term prediction of achievement attitudes in mathematics and reading. Child Development, 57, 646-659.

Wagner, B. M., \& Phillips, D. A. (1992). Beyond beliefs: Parent and child behaviors and children's perceived academic competence. Child Development, 63, 1380-1391.

Weiner, B. (1985). An attributional theory of achievement motivation and emotion. Psychological Review, 92, 548-573.

Wiggins, J. S. (1973). Personality and prediction: Principles of personality assessment (pp. 277-327). Reading, MA: AddisonWesley.

Received September 17, 1993

Revision received February 21, 1995

Accepted February 23, 1995 